\section{Global Macadamia Science: Overview of the Special Section}

\author{
Craig M. Hardner ${ }^{1}$ \\ Queensland Alliance for Agriculture and Food Innovation, University of \\ Queensland, St. Lucia QLD 4072, Australia
}

Marisa Wall

USDA-ARS, Daniel K. Inouye U.S. Pacific Basin Agricultural Research Center, 64 Nowelo Street, Hilo, HI 96720

\author{
Alyssa Cho \\ University of Hawaii-Manoa, College of Tropical Agriculture and Human \\ Resources, 875 Komohana Street, Hilo, HI 96720
}

Additional index words. Macadamia integrifolia, Macadamia tetraphylla, nut crop, tree nut

\begin{abstract}
Macadamia is a rapidly developing global crop; however, limited cultivation history and size of the industry means many challenges remain to support sustained productivity and profitability of this industry. This paper summarizes oral and poster presentations, and subsequent papers included in this volume, delivered at the 2017 International Macadamia Research Symposium, held in Hilo, HI, in September of that year. This was the first international meeting of macadamia researchers since 1992 . The 28 oral and seven poster presentations covered propagation technology, tree physiology, soils and nutrition, pollination, pest and disease, orchard management, genetics and breeding, product development, and new production regions. Notable messages were that micrografting of macadamias is commercially viable; planting density and girdling could increase early yield per hectare; resource availability may limit cross-pollination yield; and yield production of individual branches is not independent. Integrated pest management was described to develop pest-resilient farming systems and manage felted coccid; an international collaborative approach was proposed for effective disease management and early detection; and the concept of integrated orchard management was used to translate research outputs into a common language for grower adoption. In the areas of breeding and genetic resources, research demonstrated that modern macadamia cultivars are two to four generations from wild but do not capture all wild diversity; progress was reported on the Macadamia Genome Project to produce the first macadamia reference genome; and advances in phenotypic selection and cultivar development were described.
\end{abstract}

Received for publication 4 Sept. 2018. Accepted for publication 11 Dec. 2018.

This paper summarizes oral and poster presentations, and subsequent papers included in this special section that were delivered at the 2017 International Macadamia Research Symposium, held in Hilo, HI, in September of that year.

This paper was supported in part through the project "MC16000: Contribution to the 2nd International Macadamia Research Symposium 2017" through funding by Hort Innovation, using the macadamia research and development levy and contributions from the Australian Government.

Craig Hardner's contribution to this paper was jointly supported by the Department of Agriculture and Fisheries, the University of Queensland, and Hort Innovation Australia using funds from the macadamia industry and the Australian Government.

We thank the U.S. Department of Agriculture Agricultural Research Service, Hawaiian Macadamia Nut Association, Island Princess, Hamakua Nut Company, MacFarms, Crop Production Services, Mauna Loa, Hawaiian Host, Olson Trust, and Hort Innovation for financial and in-kind support for the 2017 International Macadamia Research Symposium.

${ }^{1}$ Corresponding author. E-mail: c.hardner@uq.edu. au. search is being undertaken in many countries to address these challenges, the relatively small size of the industry in each country means that there are opportunities to more efficiently address common challenges by improving communication among the international macadamia research community.

The 2017 International Macadamia Research Symposium was held on 13 and 14 Sept. in Hilo, HI. The symposium attracted 99 attendees from Australia, Brazil, China, Haiti, Japan, Mexico, New Zealand, Poland, Switzerland, and the United States (Fig. 1). A total of 11 students attended. This paper reviews the oral and poster presentations made at the 2017 International Macadamia Research Symposium, held to support greater communication among the international community of macadamia researchers. This is the first international macadamia research meeting since 1992 (Bittenbender, 1993).

\section{Summary of Presentations}

A total of 28 oral and seven poster presentations were delivered at the symposium (abstracts are included as a Supplemental File). Areas of research included propagation, tree physiology, soils and nutrition, pollination biology, pest and disease biology, orchard management, genetics and breeding, developing production areas, and product development. Seven of the presentations are published in this special section (Alam et al., 2019; Hardner et al., 2019; Howlett et al., 2019; O'Connor et al., 2019; O'Hare et al., 2019; Toft et al., 2019; Zhao et al., 2019).

Propagation. C. Searle and K. Wilson (personal communication) presented a modified method for micrografting that was commercially viable by using older budwood and a modified wedge grafting technique to produce disease free plants in 10 to 12 weeks compared with 15 to 24 months using conventional grafting methods. Benefits of micrografting are reduced nursery costs by $\approx 50 \%$, faster production, lower budwood requirement, and improved take of recalcitrant cultivars. Disadvantages are increased care in the nursery and in the field following planting out. M. Alam et al. (personal communication) reported variability in grafting success of scions of HAES 741 on seedling and cuttings of a range of intra- and interspecific rootstocks prepared to screen for dwarfing in a subsequent field trial.

Tree physiology. Several presentations (J. Wilkie et al., personal communication; T.G. Thorp and A. Smith, personal communication; B. Toft et al., personal communication) (Toft et al., 2019) discussed the physiology of young $(<4$ years of age) trees to support development of a new high-density intensive production system and underpin greater productivity. Early yield per tree (and per hectare) was $\approx 50$ times greater for the cultivar A203 than HAES 741 at age 4, primarily due to early flowering (J. Wilkie et al., personal communication) (Fig. 2). There was no significant effect of planting density on yield per tree, so that when converted to per hectare, yield was $\approx 3$ times greater at the highest density (5 m-by-2 m) compared with 


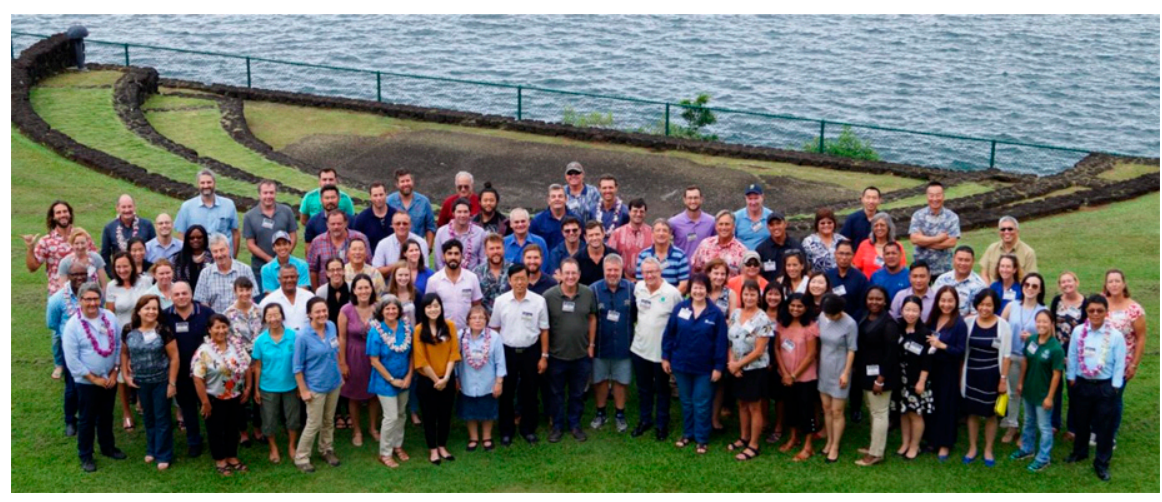

Fig. 1. Attendees at the 2017 International Macadamia Research Symposium, Hilo, HI.

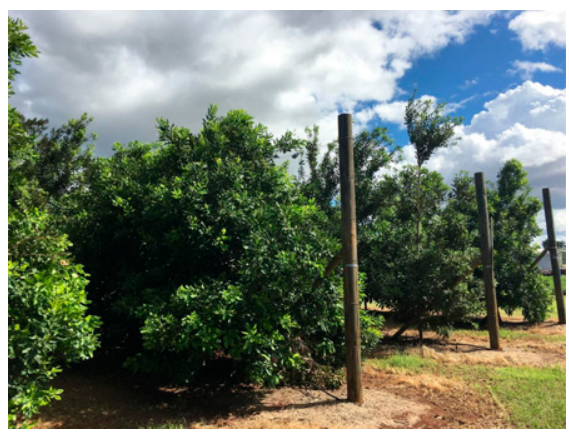

Fig. 2. Three-year-old high-density $(4.5 \times 1.5-\mathrm{m})$ planting systems trial with cultivars HAES 741 and A203. (Photo supplied by Ben Toft.)

conventional (8 m-by-4 m) planting densities. Yield (per tree and hectare) was correlated with absolute raceme production at early age, but planting density did not affect raceme production. A trend with increasing yield per hectare and light interception was detected for 'A203', but this pattern was difficult to detect in the lower-yielding HAES 741. Light interception was strongly related to canopy volume per hectare, which was primarily affected by planting density. These results demonstrate that the interaction between trees does not influence yield at a young age. Clearly, results from these trials at later age will be required to evaluate the long-term effects of planting density on yield.

Girdling (either $2 \mathrm{~mm}$ or $5 \mathrm{~mm}$ wide) doubled yield in very young (3- and 4-yearold) trees of HAES 344 grown in northern New South Wales in Australia (T.G. Thorp and A. Smith, personal communication). Repeated girdling in the subsequent year did not influence yield, relative to trees girdled once. Two years after treatment, girdled trees tended to be smaller than nongirdled trees, but this was not significant. Girdling in young trees can increase early yield, but effects may be moderated in seasons of high stress (e.g., low rainfall), and longer-term consequences of this intervention are unknown.

Branching characteristics were quantified at different scales (i.e., whole tree, primary branches, secondary branches, vegetative growth flush units, node/internode) within trees of 5 to 6 years of age and correlated with per tree yield (B. Toft et al., personal communication) (Toft et al., 2019). Canopy volume was strongly associated with trunk cross-sectional area (phenotypic correlation, $\left.r_{P}=0.82\right)$ but only moderately $\left(r_{P}=0.43\right)$ with branch cross-sectional area. Yield per tree was most strongly associated with number of nuts per tree $\left(r_{P}=0.97\right)$ (which in turn was moderately associated with nuts per branch unit, raceme length, and racemes per branch unit, $\left.r_{P}=0.47-0.69\right)$ but was virtually uncorrelated with canopy volume $\left(r_{P}=0.12\right)$. Genetic variation exists for traits that are important for high-density orchards (which require highly productive, low-vigor trees) including early (5-year) tree size, yield efficiency $\left(\mathrm{kg} \cdot \mathrm{m}^{-3}\right.$ tree canopy), and branching characteristics. However, cultivars combining very small canopy volume and very high yield were not identified in this study.

G. Chirgwin and P. Brown (personal communication) report that in a study with 10 - to 15-year-old trees, organs of branch units interact, the number of mature fruit per branch unit is correlated with the stomatal conductance $\left(g_{\mathrm{S}}\right)$ of the leaves on the unit (rather than the individual branch per se), and $g_{\mathrm{S}}$ is influenced by the quantity and quality of these leaves (and presumably light environment). These results suggest yield could be increased by maintaining high $g_{\mathrm{S}}$ of leaves either through increasing the number and quality of leaves or reducing stress.

Soils and nutrition. J. Shen et al. (personal communication) and Zhao et al. (2019) report that although the orchard estate in China is expected to become one of the largest globally in the next few years, nutrient management is poor. Chinese farmers apply general fertilizers above or over recommended rates for nitrogen and potassium; however, the application rate of phosphorus is much greater than plant requirements, leading to apparent phosphorus toxicity and deficiency of minor and trace elements. The authors also report that although macadamia forms cluster roots for mobilization of soil phosphorus without the need for mycorrhiza (typical of other proteaceous plants and in contrast to many other tree crops), successful infection of macadamia roots with mycorrhiza is possible and hypothesize this could be important for rhizosphere management. Integrated nutrient management of macadamia should consider the specific root biology of macadamia. For sustainable macadamia industry in the future, it is imperative to develop appropriate nutrient management by integrating soil amelioration, root-zone nutrient supply, fertilizer application, and rhizosphere processes.

S. Hill et al. (personal communication) reported that the current leaf sampling protocol for nutrient monitoring of mature trees could be extended from the convention of sampling leaves from only the second whorl of hardened mature terminals to include the third whorl, as there was no significant difference between these, although there were significant differences with other whorls. The experiment should be repeated over several years and other cultivars to confirm generality of results. In contrast, a proposed nondestructive indirect method based on a chlorophyll meter was poorly correlated with leaf nitrogen content (R. Galanti et al., personal communication).

Pollination. Increased nut set per raceme in late January in Australia from pollination across a number of cultivars, compared with self-pollination, was reconfirmed (B.G. Howlett et al., personal communication) (Howlett et al., 2019). Depression in yield due to selfing compared with outcrossing was consistently greater than variation in yield due to different pollen parents, except when the seed parent was A203. However, the authors suggest resource availability may limit cross-pollination yield, as there was a decreasing return in yield per tree with increasing number of racemes pollinated. G. Chirgwin and P. Brown (personal communication) appear to support these findings, as they suggested that greater vigor (and hence greater resource availability) would lead to greater yield. However, B.G. Howlett et al. (personal communication) and Howlett et al. (2019) report no significance difference in yield between cross and open-pollinated treatments, although nut set was greatest in the northern and western aspects. B. Willcox et al. (personal communication) hypothesize that cross-pollination may be more effective in increasing relative yield in low- and medium-vigor macadamia trees based on results showing this effect in avocado.

B.G. Howlett et al. (personal communication) suggested that lower nut set from open-pollination compared with hand crosspollination in single cultivar orchards demonstrates pollen deficiency. However, because of the absence of sources of unrelated pollen in monogenetic orchards, it is unlikely that introduction of pollen vectors in these orchards would improve cross-pollination and increase nut set.

In a study across seven mixed cultivar orchards in the Bundaberg region, honeybees were found to be the most frequent visitor, but temporal visitation patterns were inconsistent among years (B. Willcox et al., personal communication). Another study (L. Evans, personal communication) in a similar orchard did not detect a relationship between number of honey or stingless bees at pollination (and distance to hives) and the number of nuts set per raceme in January. L. Evans et al. (personal 
communication) also reported greater nut set for flowers opening earlier in the season and suggested a more even spread of pollination could be achieved by reducing heterogeneity in density of flowering among trees.

Insect pests. A range of pests impacts macadamia production in Australia [fruit spotting bug (Amblypelta nitida), macadamia nut borer (Cryptophlebia ombrodelta), Sigastus, Scirothrips, green vegetable bug (Nezara viridula), Vitellus, Leptocoris] (R. Huwer et al., personal communication). Although strategies have been developed to manage individual pests, a new fully integrated pest management program to develop a pest-resilient farming system has been initiated that involves research on 1) pest biology and baseline statistics, 2) improved diagnostic methods, 3) new biological control options, 4) alternative cultural practices, 5) preliminary laboratory screening of integrated pest management-compatible chemicals, 6) whole farm and regional scale testing, and 7) coleading industry adoption (R. Huwer et al., personal communication).

Macadamia felted coccid (Eriococcus ironsidei) (MFC) has developed as a significant pest in Hawaii since first detected in 2005 (A. Cho et al., personal communication). The main impact is through limb dieback and reduced production. Yield decline in the cultivar HAES 344 could be detected at low crawler densities $(<8$ crawlers per $\mathrm{cm}^{2}$ ), but yield in HAES 508 was only depressed at high concentrations of crawlers $\left(>16\right.$ crawlers per $\left.\mathrm{cm}^{2}\right)$. R. Gutierrez et al. (personal communication) reported that hedging of canopies of older trees with enhanced floor vegetation lead to reduced abundance of MFC and an increase in MFC predators and yield, compared with hedging alone, which was also better than the control. MFC predators were greatest following hedging and orchard floor vegetation enhancement (compared with hedging only and the control). In the cultivar HAES 508, yield was greater for the hedging alone, although MFC abundance was unaffected. A full economic analysis of costs of MFC on yield decline and the benefits of chemical and cultural options is required to optimize management of this pest.

Disease. O. Akinsanmi et al. (personal communication) highlighted the range of root, stem, leaf, flowers, fruit, and kernel pathogens impacting macadamia production. Some of these only occur in specific production regions, whereas others have a global presence. Disease development (and hence economic impact) depends on interaction between pathogen, environment, and host. However, increased global movement of commodities increases potential for largescale pathogen spread. It is argued that an internationally proactive collaborative approach that involves information exchange for surveillance and diagnostics, and variety testing is the best defense to resurgence or new encounters

Methods were described for development of rapid bioassay methods using young leaves for large-scale screening of macadamia germplasm for resistance to Phytophthora species. $P$. cinnamomi is the major root and trunk pathogen in Australia that causes reduced productivity through poor vigor and tree death (O. Jeff-Ego, personal communication). Results indicated that fresh leaves were more susceptible to infection than older leaves, and susceptibility varied among cultivars. Further work is required to confirm correlation between leaf and field performance.

Orchard management. J. Mollinedo et al. (personal communication) reported that, using the same orchard treatments described previously by R. Gutierrez et al. (personal communication), the soil density of orchards that had enhanced floor vegetation following hedging was $9 \%$ to $22 \%$ lower than that for control orchards. However, results were inconsistent for hedging treatment alone, or for water infiltration and moisture content.

Annual planting, yield, and kernel quality data have been collected from $\approx 270$ Australian farms since 2009 to benchmark production and identify opportunities for improvement (G. Slaughter et al., personal communication). Additional financial data from a subset of 48 farms supported the development of the Financial Planner for Macadamia that can be used to evaluate management and investment options for improved efficiency and long-term farm productivity and profitability.

The concept of an integrated orchard management guide to combine 30 years of diverse research publications and industry factsheets using a common vocabulary to support grower education and adoption was presented (J. Bright et al., personal communication). The guide summarizes production as the interaction among the pillars of canopy, orchard floor, and drainage across five stages of orchard development. The concept of red flags was used to identify developing issues in the orchard and actions that growers could use to address these issues.

The opportunity for remote sensing to assist orchard management was discussed (R. Willcox et al., personal communication) and a moderate $\left(r^{2}=0.6\right)$ relation between individual tree vigor (assessed using remote sensing) and yield was found.

Genetics and breeding. Almost one-third of presentations discussed genetics and breeding of macadamia. The major themes covered were genetic structure of wild and cultivated germplasm; opportunities, challenges, and progress from breeding; opportunities from use of interspecific germplasm; and genomic technologies.

Two presentations (C. Peace et al., personal communication; C.M. Hardner et al., personal communication) demonstrated that modern cultivars are only several generations from the wild subtropical forest origins in eastern Australia. Molecular marker analysis indicated that there is a strong geographic structure to genetic diversity of wild populations. Wild origin explains the greatest differences between cultivars, with Hawaiian cultivars tracing back to the northern distribution of $M$. integrifolia, the region with the lowest genetic diversity. Australian selections are more diverse; however, few of these cultivars also originate from the more diverse southern distribution of $M$. integrifolia. Cultivars that are hybrids between $M$. integrifolia and the other edible species, M. tetraphylla, appear to have arisen during cultivation rather than derived directly from natural hybrid zones. Comparison of genetic variation between older plantings and current remnant wild populations suggest a loss of diversity since European colonization. C. Peace et al. (personal communication) highlighted the opportunity of genotyping all remnant wild trees to develop a baseline description of the genetic diversity using the foundation of the original wild allelic diversity and structure.

M. Alam et al. (personal communication) and Alam et al. (2019) presented results from different marker systems demonstrating that the genetic fingerprint of biological and technical replicates of two globally important Hawaiian cultivars, Keaau (HAES 660) and Mauka (HAES 741), were near isogenic. In addition, there were very few significant phenotypic differences. Historical records indicate that they were sampled from the same orchard, possibly even the same tree.

Given the limited breeding history, there appears to be great potential to develop new cultivars (C. Peace et al., personal communication; B. Topp et al., personal communication). The first field trials of the Australian Macadamia Breeding Program were established in 1997 and 1998 (C.M. Hardner et al., personal communication) (Hardner et al., 2019). The program employed a quantitative genetic approach to balance accuracy of prediction of long-term performance against selection intensity and evaluation costs (determined by size of the progeny population, planting density, length of evaluation period, and frequency of assessment). A selection index using economic weights for yield, kernel recovery, tree size, and kernel quality derived from a bio-economic model of production and processing over a 20 -year period was used to identify elite seedling progeny that were clonally propagated for further evaluation in multilocation regional variety trials. Four new cultivars from these selections were released in 2017 (B. Topp et al., personal communication). The Yunnan Institute of Tropical Crops initiated a breeding program in Yunnan in 1993 and have selected several varieties (B. Xu et al., personal communication).

B. Topp et al. (personal communication) discussed the use of quantitative genetics, cooperative field trials with growers, and poly-cross mating in the current Australian Macadamia Breeding Program to address challenges of large tree size, cultivar longevity, securing stable funding, and length of evaluation period. They also suggested selection for canopy architecture, increased precocity and self-compatibility, and disease resistance; exploitation of more diverse intraand interspecific germplasm from the wild; and use of genome-wide selection as further options to address these challenges. 
Two presentations (J. Neal et al., personal communication; C. McConchie et al., personal communication) examined interspecific differences in kernel quality traits. Average timing to $90 \%$ kernel oil content of M. ternifolia kernels was significantly earlier (mid-December in Australia) than for other germplasm classes ( $M$. integrifolia, $M$. tetraphylla, and their hybrids with M. ternifolia and $M$. jansenii), which occurred in midFebruary-although this is somewhat earlier than reported in other $M$. integrifolia and $M$. tetraphylla studies. Maximum oil content of M. tetraphylla kernels (56\%) was significantly lower compared with all other germplasm classes (65\% to $70 \%)$, although these are lower than reported by others and may be a consequence of the method used.

Assessment of color of kernels from five wild $M$. tetraphylla genotypes and three commercial cultivars (HAES 246, HAES 344, HAES 849) before and following six roasting treatments indicated that $M$. tetraphylla samples were significantly paler before roasting, but the response across the treatments was similar for all genotypes, with M. tetraphylla kernels consistently lighter (C. McConchie et al., personal communication). No significant difference in sugar concentration of M. tetraphylla kernels compared with the $M$. integrifolia samples was reported. These results suggest that although segregation on raw kernel color could be used to produce uniform product, the conventional dogma that the roasting responses of $M$. tetraphylla and $M$. integrifolia are different is not supported.

C. Nock et al. (personal communication), K. O'Connor et al. (personal communication), and O'Connor et al. (2019) discussed progress and opportunities from new genomic approaches. The Macadamia Genome Project aims to produce the first macadamia reference genome (C. Nock et al., personal communication) using the Hawaiian cultivar 741 as a fundamental resource for future genetics and breeding studies. Genome and transcriptome sequence data were used to develop an annotated gene space released in 2016 (Nock et al., 2016). Currently, additional Illumina short-read and PacBio longread sequence data, a bioinformatics pipeline that incorporates transcriptome data in the de novo assembly process, and a dense linkage map are being used to improve anchoring and orientation of genome scaffolds.

Initial results from a genome-wide association study identified six to nine Diversity Array Technology (DArT) single-nucleotide polymorphism markers possibly linked to significant variation in nut size and three markers linked to kernel recovery - a highly heritable component trait of yield (K. O'Connor et al., personal communication) (O'Connor et al., 2019). Further work is needed to validate the utility of these markers before their use in screening young progeny and selecting for these traits before establishment of progeny field trials.

Product development. Macadamia kernels contain $\approx 76 \%$ oil, of which $79 \%$ to
$86 \%$ is mono- or poly-unsaturated and increasing levels could support opportunities for health claims (T.J. O'Hare et al., personal communication) (O'Hare et al., 2019). These authors report desaturation of $\mathrm{C} 18: 0$ to $\mathrm{C} 18: 1$ is much more efficient than for $\mathrm{C} 16: 0$, suggesting that increasing the rate of elongation of C16:0 followed by increasing desaturation of C18:0 may be the most efficient strategy for producing greater unsaturated oils. Genetic variation suggests opportunities for modifying oil profile through breeding.

Although the kernel of macadamia is a premium product, approximately $70 \%$ of the fruit, which is shell and husk, is generally treated as waste or low-grade product. R. Shi et al. (personal communication) reported that biological tests of husk extracts indicated whitening activity that could be useful in cosmetics, the lignin of the shell could be suitable as a natural filter material, and the high essential oil of the flowers may have a use as perfume.

New production regions. Rapid development of the Chinese macadamia industry was reported (B. Xu et al., personal communication; J. Shen et al., personal communication). Production has increased to $12,000 \mathrm{t}$ nut-in-shell from a very low base in 2008 . Yunnan province accounts for $90 \%$ of production. Intercropping is used for soil cover. Current research challenges include breeding, soil and nutrition management, disease management, processing methods, and product development.

Macadamia was planted on a limited scale in Nepal in the 1970s (A. Barrueto et al., personal communication). However, recently developed land-suitability models used to examine crop resilience and long-term viability suggest macadamia is suitable for wider planting in Nepal, with expansion possible under future climate scenarios (A. Barrueto et al., personal communication). Similar to other countries, macadamia is primarily grown by wealthier farmers in Nepal, and alternative business models are required to enable benefits to be shared with women and poorer farmers.

In Mexico, participatory social economic research of a current small-scale, macadamiacattle system in the cloud mountain forests of Tlalnelhuayocan suggest that reasonable production from macadamia is possible (production starting year 6 , yield up to $4 \mathrm{t} / \mathrm{ha}$ ) but is limited by lack of horticultural knowledge and impact of P. cinnamomi (G.S. Quintas and O.A. Valdés Rodríguez, personal communication). A mixed production system offers the possibility for communal landowners to become involved in macadamia production while spreading risk, but further work on the kernel sanitation may be required.

\section{Conclusions}

The 2017 International Macadamia Research Symposium demonstrated that there is a wide diversity of research being undertaken worldwide to support local macadamia industries, including new production areas such as China, Mexico, and Nepal. Although the priority of different research areas will vary with the stage of industry development, local abiotic and biotic conditions, and product development, common challenges were apparent. These included the lack of horticultural knowledge in new growing areas, knowledge of physiology to support intensification of orchard management, quantitative data on pollination and yield to support pollen vector management, genetic improvement, integrated pest and orchard management, development of new products to add value, and international collaboration to support research efficiency. Although advances within individual science disciplines in macadamia are still required to support improved knowledge, systems and interdisciplinary research such as genetic improvement, integrated pest and orchard management, and improved understanding of interaction among genotype, environment, and management are vital for the development of ecological and sustainable orchards in the future including adaptation to climate change.

\section{Literature Cited}

Alam, M., C. Hardner, C. Nock, K. O'Connor, and B. Topp. 2019. Historical and molecular evidence of genetic identity of macadamia cultivars HAES741 and HAES660. HortScience 54:616-620.

Anon. 2018. Yearbook 2017. Australian Macadamia Society, Lismore NSW, Australia.

Bittenbender, H.C. 1993. Proceedings of the First International Macadamia Research Conference, Kona Hilton, Kailua-Kona, HI, 28-30 July 1992. The Service, Honolulu, HI.

Hardner, C., J. Costa e Silva, E. Williams, N. Meyers, and C. McConchie. 2019. Breeding new cultivars for the Australian macadamia industry. HortScience 54:621-628.

Hardner, C.M., C. Peace, A.J. Lowe, J. Neal, P. Pisanu, M. Powell, A. Schmidt, C. Spain, and K. Williams. 2009. Genetic resources and domestication of macadamia, p. 1-125. In: J. Janick (ed.). Horticultural reviews. John Wiley \& Sons, Hoboken, NJ.

Howlett, B.G., S.F.J. Read, M. Alavi, B.T. Cutting, W.R. Nelson, R.M. Goodwin, S. Cross, T.G. Thorp, and D.E. Pattemore. 2019. Crosspollination enhances macadamia yields, even with branch-level resource limitation. HortScience 54:609-615.

Nock, C.J., A. Baten, B.J. Barkla, A. Furtado, R.J. Henry, and G.J. King. 2016. Genome and transcriptome sequencing characterises the gene space of Macadamia integrifolia (Proteaceae). BMC Genomics 17:937.

O'Connor, K., B. Hayes, C. Hardner, M. Alam, and B. Topp. 2019. Selecting for nut characteristics in macadamia using a genome wide association study. HortScience 54:629-632.

O'Hare, T.J., H.H. Trieu, B. Topp, D. Russell, S. Pun, C. Torrisi, and D. Liu. 2019. Assessing fatty acid profiles of macadamia nuts. HortScience 54:633-637.

Toft, B.D., M.M. Alam, J.D. Wilkie, and B.L. Topp. 2019. Phenotypic association of multiscale architectural traits with canopy volume and yield: Moving toward high-density systems for macadamia. HortScience 54:596-602.

Zhao, X., Q. Dong, S.B. Ni, X.Y. He, H. Yue, L. Tao, Y. Nie, C.S. Tang, F.Q. Zhang, and J. Shen. 2019. Rhizosphere processes and nutrient management for improving nutrient-use efficiency in macadamia production. HortScience 54:603-608. 